\title{
Synergistic effects of micro-abrasion-corrosion of UNS S30403, S31603 and S32760 stainless steels
}

\author{
J.O. Bello*, R.J.K. Wood, J.A. Wharton \\ Surface Engineering and Tribology Group, School of Engineering Sciences, University of Southampton, \\ Highfield, Southampton SO17 1BJ, United Kingdom
}

Received 29 August 2006; received in revised form 21 December 2006; accepted 22 December 2006

Available online 23 May 2007

\begin{abstract}
In this study, the synergistic effects of abrasion and corrosion on UNS S30403, S31603 and S32760 stainless steels have been investigated using a micro-abrasion test rig. The stainless steel samples have been studied under both pure abrasion (PA) and abrasion-corrosion (AC) conditions simulated by using silicon carbide based slurries in either distilled water or 3.5\% sodium chloride solutions. Tests have been conducted at various abrasive concentrations $\left(0.006-0.238 \mathrm{~g} / \mathrm{cm}^{3}\right)$ and at 38 and $180 \mathrm{~m}$ sliding distance to enable the interactions between abrasion and corrosion to be better understood. Wear mode identification and regime mapping was used to establish the dominant wear mechanism at the different slurry concentrations. The synergistic effect has been quantified and related to the material composition and the grooving or rolling abrasive wear mechanisms present. The synergistic levels were typically positive and have been discussed in terms of their dependence on the integrity of the passive films and the repassivation kinetics. The three-body abrasion-corrosion rates for all steels were found to be 14 times higher than two-body abrasion-corrosion rates. S30403 shows weak repassivation performance with electrochemical activity being proportional to mechanical activity. S31603 showed a constant electrochemical activity over a variety of mechanical conditions, indicating a stronger repassivation performance than S30403. S32760 has the best repassivation performance with negative synergistic characteristics until abrasion rate are such that depassivation occurs and the electrochemical activity is then comparable to the other steels.
\end{abstract}

(C) 2007 Elsevier B.V. All rights reserved.

Keywords: Abrasion-corrosion; Stainless steels; Synergy; Passivation; Micro-abrasion

\section{Introduction}

In selecting materials for engineering applications, especially in conditions where corrosion is an issue, stainless steels usually receive greater preference over other metals due to their inherent corrosion resistance properties attributed to the continuous formation of a passive oxide layer on the surface. However, when such applications involve sliding against other materials, a combination of mechanical (abrasion) and electrochemical (corrosion) processes takes place, termed abrasion-corrosion. The electrochemical activity is enhanced by abrasion due to abradants disrupting the integrity of the passivating oxide layer. In this context, abrasion-corrosion will be defined as the mechanical abrasion of a metal surface and the subsequent deterioration of the metal by the combined influence of cor-

\footnotetext{
* Corresponding author. Tel.: +44 2380598748.

E-mail address: bjo@ soton.ac.uk (J.O. Bello).
}

rosion and mechanical damage. The combined effect, often termed synergy, of abrasion and corrosion can lead to greater damage than simply the summation of the two parts and as a result can considerably shortens the service life of components. Research interest in the abrasive and abrasive-corrosive properties of stainless steels has increased considerably in recent times [1-3]. Acselrad et al. using the micro-abrasion ball-cratering test showed that abrasive wear performance of S30403 stainless steel is strongly influenced by the post-manufacture treatment applied to the sample [1]. Their results show that samples that were chemically treated wear at a rate approximately $25 \%$ faster than those that the cooling rates were carefully controlled. Similarly, other authors have also investigated the abrasive wear of laser-produced stainless steels and 304L with emphasis on metallurgical and micro-mechanical properties of the materials $[2,3]$.

Significant effort has been undertaken into developing a greater understanding of the abrasion-corrosion wear properties of stainless steels and for a range of different applications 
[4-11]. Stainless steels are known to have the ability to form a protective passive film on their surface when exposed to a corrosive media. However, when such exposure is combined with some form of mechanical action (such as abrasion or sliding motion), the passive oxide film can be locally or evenly destroyed. Garcia et al., adopting a ball-on-disc (stainless steel disc against an alumina ball) test method, have studied the passivation of $\mathrm{S} 31603$ in the presence of a $0.5 \mathrm{M} \mathrm{H}_{2} \mathrm{SO}_{4}$ solution [5]. A passive range was observed which could be divided into three regions based on the applied load. Below $2 \mathrm{~N}$, no passive film breakdown occurred. However, between 2 and $12 \mathrm{~N}$, removal of passive oxide film on $\mathrm{S} 31603$ sample resulted from of periodic delamination of the oxide. Above $12 \mathrm{~N}$, a relationship between the thickness of the passive oxide film and wear rate could not be established because both film and the bulk material were worn simultaneously [5]. Lee and Shih [11] studied the abrasive corrosive wear of plasma-nitrided alloy steels of type UNS S30400, UNS S41000 and UNS G41400 in a tribotest in which the specimen was held under potentiostatic control at anodic and cathodic potentials in $3 \%$ sodium chloride $(\mathrm{NaCl})$ solution (pH 6.8). The stainless steel materials studied showed significant weight loss as the applied potentials was increased anodically. The wear rate and coefficient of friction was found to decrease in the order UNS S30400>UNS S41000>UNS G41400 [11].

Thomann et al. compared the wear-corrosion properties of two biocompatible stainless steels; S31603 and Rex 734, used for biomedical applications; with specially developed alloy steel (P558). Their experiments used an aerated 22\% $\mathrm{NaCl}$ solution at temperatures ranging between room temperature and $80^{\circ} \mathrm{C}$, and they found that although the P558 alloy is not the cheapest, it has superior wear resistance and mechanical properties [6]. Dearnley suggested an alternative way of improving the resistance of S31603 stainless steel to surface degradation by applying a thin $(6-8 \mu \mathrm{m})$ plasma-based hard cathodic coating of $\mathrm{CrN}$ and an experimental S-phase [7]. The success of this approach depended on the nature of the pervading corrosion-wear mechanisms.

As discussed above the stainless steels depend on a passive film for their corrosion resistance and damage to this passive surface layer will typically result in localised and accelerated corrosion. Such damage or fracture leads to depassivation and can be instigated by wear processes such as abrasion or sliding between the steel surface and a counter-body. The wear processes can lead to disruption and/or removal of the thin (10-100 nm for stainless steels) passive layer resulting in discontinuous layers or highly reactive nascent surfaces that induce accelerated electrochemical activity (current) by micro-galvanic coupling between worn areas and unworn areas. This results typically in increased material removal when wear and corrosion act together. Goldberg and Gilbert [12] has suggested an equation in which the current transient $(I(t))$ and repassivation current by single scratch test could be modelled and predicted. Oxide film fracture due to mechanical sliding according to the following equation:

$I(t)=I_{\text {peak }} \mathrm{e}^{-\left(t-t_{0}\right) / \tau}+I_{\infty}$ where $I_{\text {peak }}$ is the peak current given by $I_{\text {peak }}=I_{\max }-I_{\infty}, \tau$ the time constant for repassivation, $\tau_{0}$ the time to produce the scratch, and $I_{\infty}$ is the baseline current at $t=\infty$. Thus, the value of $\tau$ is a critical characteristic of surfaces and relates to the repassivation kinetics of the tribo-system.

Mischler et al. have proposed a model (see Eq. (2)) to calculate the average current per stroke, $I_{\mathrm{p}, \text { av }}$ during a reciprocating wear-accelerated corrosion test (Pin-on-Plate) of passive metals in tribocorrosion systems by considering the real depassivated area [13]:

$I_{\mathrm{p}, \mathrm{av}}=K_{\mathrm{st}} L f\left(\frac{F_{\mathrm{N}}}{H}\right)^{0.5} Q_{\mathrm{p}}$

where $K_{\text {st }}$ is a proportionality factor which includes the probability of depassivation of a contacting surface element, $L$ the pin displacement, $f$ the stroke frequency, $F_{\mathrm{N}}$ the normal applied load and $H$ is the surface hardness. The charge per unit surface area serving for repassivation and film growth during one cycle $Q_{\mathrm{p}}=\int_{0}^{1 / f} i \mathrm{~d} t$ was determined by separate galvanostatic or potentiostatic experiment. The authors concluded that in order to understand the mutual interactions between mechanical and electrochemical parameters under sliding wear conditions, it is necessary to consider the tribocorrosion system as a whole, including the behaviour of the rubbing pin and possible role of wear debris. The proposed model was found to correctly predict the influence of sliding velocity, stroke length, and frequency, and of applied normal load on the wear-accelerated corrosion rate of different passivating metals and alloys [13]. The model has also been applied successfully in other areas of wearcorrosion $[14,15]$.

In spite of the considerable effort that has been invested into understanding the abrasion-corrosion of stainless steels, it appears little progress has been made to quantify the amount of synergy during abrasion-corrosion of stainless steels. In-depth understanding of the subject of abrasion-corrosion cannot be achieved without a clear view of the role of synergy. It is therefore the aim of this paper to further clarify the important role synergy plays in the understanding of the abrasion-corrosion of three grades of stainless steels, UNS S30403, S31603 and S32760, using the micro-abrasion test method. The reason for the selection of these materials is mainly due to the expected variety in their repassivation rates. The super duplex stainless steel (S32760) has the strongest passivation tendency with the low-carbon molybdenum austenitic stainless steel (S31603) having an intermediate tendency while the low-carbon austenitic stainless steel (S30403) has the lowest tendency. This variation in corrosion resistance is largely due to the composition of each steel sample is shown in Table 1 and related to the levels of $\mathrm{Cr}$ and Mo present. Hence, adopting the Adachi and Hutchings [16] wear mode mapping as a starting point to establish abrasive severities over a range of abrasive concentrations, effort will be made to (1) quantify the amount of synergy involved during abrasion-corrosion tests; (2) establish the nature of the synergy and its physical meaning and its effect on the overall performance of the stainless steel materials. 
Table 1

Stainless steel chemical composition

\begin{tabular}{llrlllll}
\hline & \multicolumn{7}{c}{ Composition $($ wt.\%) } \\
\cline { 2 - 7 } & $\mathrm{Cr}$ & \multicolumn{1}{c}{$\mathrm{Ni}$} & $\mathrm{Mo}$ & $\mathrm{Mn}$ & $\mathrm{S}$ & $\mathrm{C}$ & $\mathrm{Fe}$ \\
\hline UNS S30403 & 18.06 & 9.24 & 0.08 & 1.48 & 0.006 & 0.02 & Balance \\
UNS S31603 & 16.41 & 10.10 & 2.07 & 1.30 & 0.008 & 0.02 & Balance \\
UNS S32760 & 25.33 & 7.08 & 3.77 & 0.55 & 0.001 & 0.019 & Balance \\
\hline
\end{tabular}

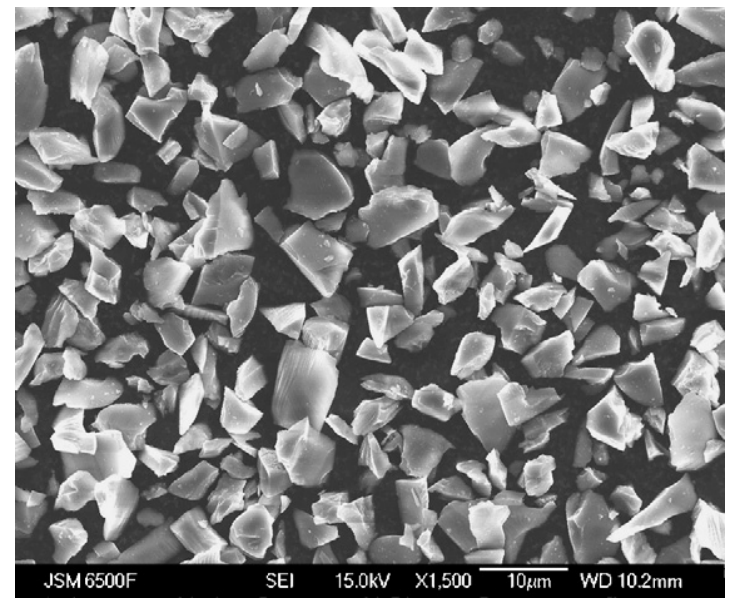

Fig. 1. SEM of SiC abrasives used in the slurry with a mean particle size of $\sim 4.5 \mu \mathrm{m}$.

\section{Experimental details}

\subsection{Sample preparation}

UNS S30403, S31603 and S32760 stainless steels were cut into test samples of $20 \mathrm{~mm} \times 10 \mathrm{~mm}$. The samples were polished to produce a surface roughness of approximately $1 \mu \mathrm{m}$ The samples were kept in a desiccator throughout the test programme. The abrasive slurry was prepared by mixing a known weight of dry F1200 silicon carbide (SiC) particles (mean particle size of $\sim 4.5 \mu \mathrm{m}$, see Fig. 1) in either distilled water, for the pure abrasion (PA) tests or in a $3.5 \% \mathrm{NaCl}$ solution, for the abrasion-corrosion (AC) tests to give a series of abrasive volume fractions ranging from 0.006 to 0.238 . The hardness of the abrasive particles was $2500 \mathrm{Hv}$. The hardness of the S30403, S31603 and S32760 samples, measured using a standard Vickers hardness tester, were approximately 223,175 and $328 \mathrm{Hv}$, respectively. The chemical compositions of the three stainless steels are detailed in Table 1 and the mechanical/physical properties are presented in Table 2.

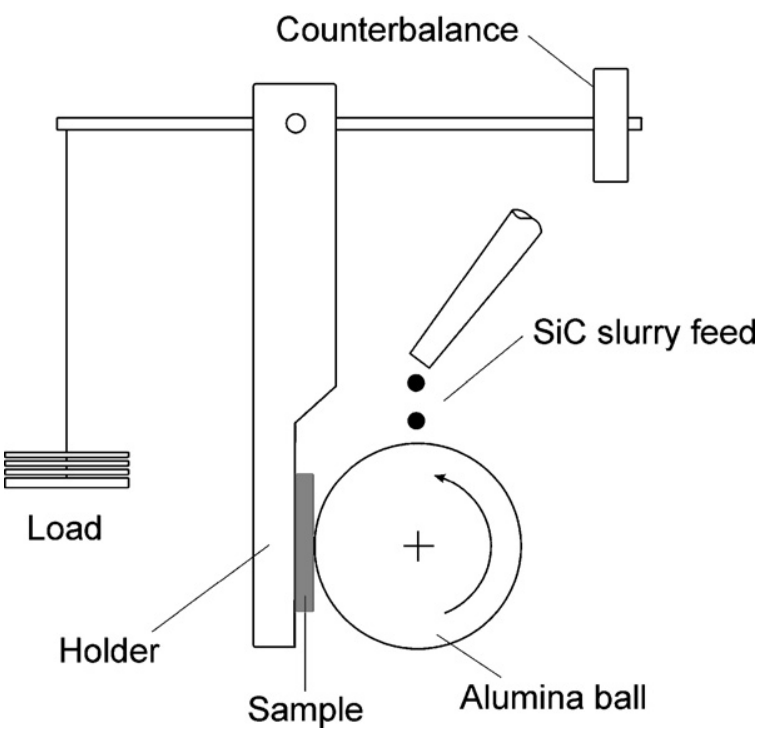

Fig. 2. Schematic of the micro-abrasion ball-cratering test rig.

\subsection{Methodology}

The experiments were performed using a commercially available micro-abrasion test apparatus, the Phoenix Tribology TE66 Micro-Scale Abrasion Tester. A schematic diagram of the apparatus is shown in Fig. 2. The samples were secured in the holder and loaded against the ball, which is held by friction and able to rotate parallel to the plane of the sample, while the slurry is drip-fed onto the ball at the rate of $0.1\left(\mathrm{~cm}^{3} / \mathrm{s}\right)$. The geometry of the imposed wear scar is spherical. A conditioned alumina ball (with a roughened wear track by separate tests on virgin steel samples) with a diameter of $22 \mathrm{~mm}$ was used as the counterface, having a surface roughness of $R_{\mathrm{a}} \sim 1 \mu \mathrm{m}$ and hardness of $1100 \mathrm{Hv}$. To prevent the $\mathrm{SiC}$ abrasives from settling out the slurry was constantly agitated with the aid of a magnetic stirrer. The test conditions are detailed in Table 3. For the pure abrasion (PA) tests, the slurry used was made with distilled water only, while the slurry for the abrasion-corrosion (AC) tests was made with a corrosive $3.5 \% \mathrm{NaCl}$ solution. For each test condition, three measurements were made to ascertain the repeatability of the tests. Post-test analysis of the samples was conducted by a field emission gun scanning electron microscope (FEG-SEM).

\subsection{The wear rate}

For micro-abrasion tests, the wear is usually measured in two ways: either by measuring the displacement or depth of wear scar with respect to the machine frame using a transducer or alter-

Table 2

Stainless steel mechanical properties

\begin{tabular}{lllll}
\hline Names/properties & Density $\left(\mathrm{kg} / \mathrm{cm}^{3}\right)$ & Tensile strength Min. $(\mathrm{MPa})$ & Elastic modulus $(\mathrm{GPa})$ & 193 \\
\hline UNS S30403 & 8.03 & 485 & 193 & 223 \\
UNS S31603 & 8.03 & 485 & 200 & 175 \\
UNS S32701 & 7.80 & 795 & 328 \\
\hline
\end{tabular}


Table 3

Details of the micro-abrasion test conditions

\begin{tabular}{llll}
\hline Test conditions & Quantities & \\
\cline { 2 - 4 } & PA & AC & RC \\
\hline Load $(\mathrm{N})$ & 0.25 & 0.25 & 0.05 \\
Speed $(\mathrm{m} / \mathrm{s})$ & 0.05 & 25 & 0.05 \\
Temperature $\left({ }^{\circ} \mathrm{C}\right)$ & 25 & $\mathrm{~N} / \mathrm{A}$ & 25 \\
Slurry concentration $\left(\mathrm{g} / \mathrm{cm}^{3}\right.$ of distilled water) & $0.006,0.03,0.072,0.135,0.238$ & $0.006,0.03,0.072,0.135,0.238$ \\
Slurry concentration $\left(\mathrm{g} / \mathrm{cm}^{3}\right.$ of $3.5 \% \mathrm{NaCl}$ solution) & $\mathrm{N} / \mathrm{A}$ & 0.1 & $\mathrm{~N} / \mathrm{A}$ \\
Slurry feed rate $(\mathrm{cm} 3 / \mathrm{s})$ & 0.1 & 38,180 & $\mathrm{None}$ \\
Sliding distance $(\mathrm{m})$ & 38,180 & $\mathrm{Al}_{2} \mathrm{O}_{3}$ & 0.1 \\
Counterface material & $\mathrm{Al}_{2} \mathrm{O}_{3}$ & 38,180 \\
\hline
\end{tabular}

natively the wear crater dimension (diameter) can be measured using a calibrated eyepiece. In this paper the latter method was used. The wear volume was calculated using an approximate formula, assuming the spherical cap geometry of the ball, Eq. (3):

$V \approx \frac{\pi b^{4}}{64 R}$ for $b \ll R$

where $V, b$ and $R$ are the volume of wear, diameter of crater and radius of the ball, respectively. The specific wear rate, $k$, was estimated by dividing the wear volume from Eq. (3) by the applied load, $N$ and total sliding distance, $L$, see Eq. (4):

$V=k L N$

\subsection{Potentiodynamic polarisation}

Potentiodynamic polarisation measurements were carried out in a closed three-electrode cell in order to assess the corrosion behaviour of the three samples, with a sweep rate of $0.2 \mathrm{mV} / \mathrm{s}$ using a Gamry PC4-750 potentiostat and CMS100 software. The samples were secured in a electrochemical cell with an exposed area of $1.1 \mathrm{~cm}^{2}$ to be accessed by the test electrolyte, $3.5 \%$ sodium chloride $(\mathrm{NaCl})$ solution at room temperature $\left(20^{\circ} \mathrm{C}\right)$. The counter electrode was graphite and the reference electrode was a silver/silver chloride $(\mathrm{Ag} / \mathrm{AgCl})$ electrode.

\section{Results and discussion}

\subsection{Wear mode mapping}

The micro-abrasion test critically depends on the nature of the abrasive within the contact zone; whether the abrasive particles roll producing multiple indents or slide causing grooving abrasion. Adachi and Hutchings [16] have developed a principle to determine the wear regimes in which two-body grooving abrasion or three-body rolling abrasion is dominant. This is important because it allows an initial prediction of the wear mechanism. Fig. 3 shows the wear mode map for all the abrasive concentrations for the three stainless steels investigated. A mixed-mode region exists between two- and three-body abrasion, where a combination of the two wear mechanisms can occur simultaneously. The difference in performance of the stainless steels in Fig. 3 is due to the variations in hardness ratio between the stainless steels and the alumina ball.

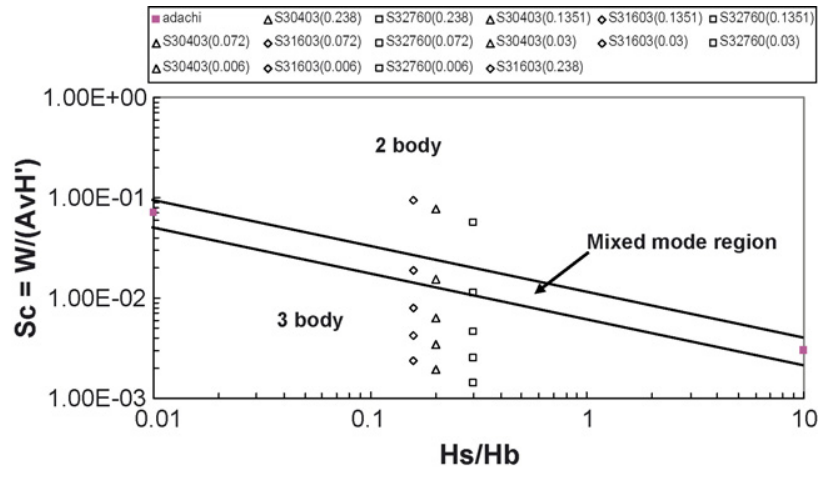

Fig. 3. Wear mode mapping at the various abrasive volume fractions used for the micro-abrasion tests. Test materials: UNS S30403, S31603 and S32760 stainless steel types. $S_{\mathrm{c}}$ is severity of contact, $W$ the applied load, $A$ the interaction area (wear scar), $v$ the volume fraction of abrasive, $H_{\mathrm{s}}$ the hardness of sample and $H_{\mathrm{b}}$ is the hardness of counterface ball.

\subsection{Wear rate versus volume fraction of abrasives}

The pure abrasive (PA) and abrasive-corrosive (AC) wear tests at $180 \mathrm{~m}$ sliding distance (SD) are shown for the three stainless steel types in Table 4 and Fig. 4. The specific wear rate, $k$, increases with increasing abrasive volume fraction for both PA and $\mathrm{AC}$ tests, for all the three stainless steels. From Fig. 4 it can be seen that a linear relationship exists between $k$ and abrasive volume fraction between the values 0.03 and 0.135 (mixed mode to three-body). This range represents an increase in the slurry concentration by a factor of 4.5 with the resulting $k$ increasing by a greater factor of 6.2 for AC and 7.0 for PA tests. This suggests

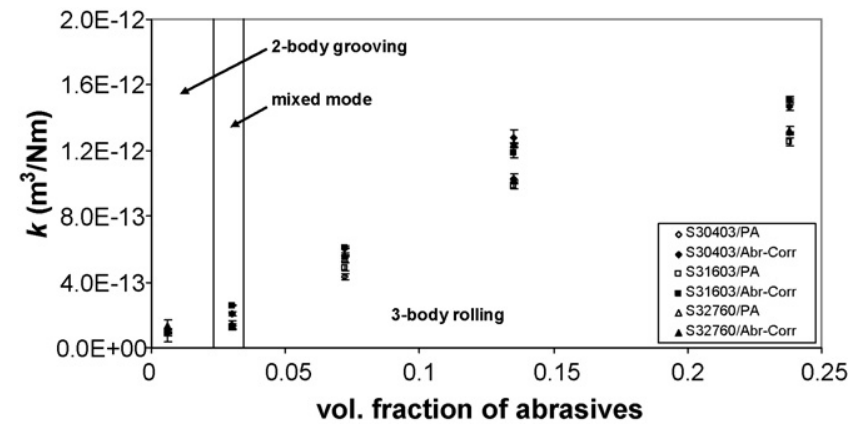

Fig. 4. Specific wear rates for abrasion and abrasion-corrosion tests on UNS S30403, S31603 and S32760 and a sliding distance of $180 \mathrm{~m}$. 
Table 4

Specific wear rates vs. volume fraction of $\mathrm{SiC}$ abrasive

\begin{tabular}{|c|c|c|c|}
\hline \multirow[t]{2}{*}{ Volume fraction } & \multicolumn{3}{|c|}{ Specific wear rate, $k\left(\mathrm{~m}^{3} / \mathrm{Nm}\right)$} \\
\hline & $\mathrm{PA}$ & $\mathrm{AC}$ & $C_{1}$ \\
\hline \multicolumn{4}{|l|}{ S30403 } \\
\hline 0.006 & $9.08 \times 10^{-14}$ & $1.12 \times 10^{-13}$ & $1.25 \times 10^{-14}$ \\
\hline 0.030 & $1.43 \times 10^{-13}$ & $2.06 \times 10^{-13}$ & $1.25 \times 10^{-14}$ \\
\hline 0.072 & $4.34 \times 10^{-13}$ & $6.03 \times 10^{-13}$ & $1.25 \times 10^{-14}$ \\
\hline 0.135 & $1.03 \times 10^{-12}$ & $1.28 \times 10^{-12}$ & $1.25 \times 10^{-14}$ \\
\hline 0.238 & $1.31 \times 10^{-12}$ & $1.47 \times 10^{-12}$ & $1.25 \times 10^{-14}$ \\
\hline \multicolumn{4}{|l|}{ S31603 } \\
\hline 0.006 & $1.06 \times 10^{-13}$ & $9.36 \times 10^{-14}$ & $8.01 \times 10^{-14}$ \\
\hline 0.030 & $1.23 \times 10^{-13}$ & $2.59 \times 10^{-13}$ & $8.01 \times 10^{-14}$ \\
\hline 0.072 & $4.89 \times 10^{-13}$ & $6.09 \times 10^{-13}$ & $8.01 \times 10^{-14}$ \\
\hline 0.135 & $9.87 \times 10^{-13}$ & $1.19 \times 10^{-12}$ & $8.01 \times 10^{-14}$ \\
\hline 0.238 & $1.25 \times 10^{-13}$ & $1.51 \times 10^{-12}$ & $8.01 \times 10^{-14}$ \\
\hline \multicolumn{4}{|l|}{ S32760 } \\
\hline 0.006 & $1.33 \times 10^{-13}$ & $1.05 \times 10^{-13}$ & $2.88 \times 10^{-14}$ \\
\hline 0.030 & $1.42 \times 10^{-13}$ & $1.26 \times 10^{-13}$ & $2.88 \times 10^{-14}$ \\
\hline 0.072 & $5.46 \times 10^{-13}$ & $5.61 \times 10^{-13}$ & $2.88 \times 10^{-14}$ \\
\hline 0.135 & $1.02 \times 10^{-12}$ & $1.24 \times 10^{-12}$ & $2.88 \times 10^{-14}$ \\
\hline 0.238 & $1.32 \times 10^{-12}$ & $1.53 \times 10^{-12}$ & $2.88 \times 10^{-14}$ \\
\hline
\end{tabular}

that for these concentrations, the wear rate is not only directly related to the number of abrasive particles being entrained into the contact (assuming these are proportional to the slurry volume fraction) but also to the fact that three-body abrasion mechanisms are more efficient at material removal than two-body or mixed mode mechanisms. Clearly, these results suggest that when the mechanism changes from a two-body grooving to a three-body rolling the wear damage is more severe. It is reasonable to assume that material removal during three-body wear, which is characterised by multiple indentations, is more efficient than two-body wear, usually associated with micro-ploughing and/or grooving. Above a slurry concentration of 0.135 , the change in $k$ was minimal. This trend is probably due to the reduction in the contact severity $\left(S_{\mathrm{c}}\right)$ due to the reduction in the load per abrasive particle or it relates to the inability of the contact to entrain higher numbers of abrasive particles (i.e. the contact is saturated at a volume fraction of 0.135 ).

Table 4 also shows that $\mathrm{S} 32760$ performed slightly better than S30403 and S31603 for all AC tests. There is evidence that $k$ is higher for all AC tests compared to the PA tests except for the lowest abrasive volume fraction, i.e. the two-body regime. This implies that corrosive activities and tribochemical wear, within the contact zone, leads to more material removal during threebody than for mixed and two-body grooving abrasive wear. The reasons for the high PA values at low abrasive volume fractions is discussed later in Section 3.4 but clearly relates to the passive film thickness, composition, integrity and repassivation kinetics. It is thought that the rate of fracture/removal of the passive oxide film in two-body wear mode is lower than in three-body due to lower number of abrasives in the contact zone to remove the passive film.

An SEM inspection of the AC wear scars on the three stainless steels at 0.006, 0.030 and 0.238 abrasive volume fractions can be seen in Fig. 5(a)-(i). It is clear that by increasing abra- sive volume fraction the predominant wear mechanism changes from an initial two-body grooving (Fig. 5(a)-(c)), followed by mixed-mode (Fig. 5(d)-(f)) to finally three-body rolling abrasion (Fig. 5(g)-(i)), which is consistent with the wear mode mapping discussed above. In addition to the characteristic abrasion, the influence of the corrosive electrolyte appears to result in an additional corrosion activity, primarily for the S30403 stainless steel. This is evident as a partial oxide film formation and corrosion debris within the abrasion grooves and indents. Usually, when a metal is heavily cold worked, energy may be stored in the metal (in the order of $8-80 \mathrm{~kJ} / \mathrm{kg} \mathrm{mol}$ ) as a result of increased dislocation density within the microstructure [17]. A slight potential difference of a few millivolts may result between the undamaged and cold-worked areas. This may lead to quite different reaction kinetics on the affected areas resulting in different corrosion rates. Also, the continuous creation of defects and dislocation movements at microstructural interfaces (grain boundaries, inclusions and voids) at the near-surface of the stainless steels may affect the growth of the $\mathrm{Cr}_{2} \mathrm{O}_{3}$ oxide film. With a discontinuous oxide present at plastically deformed sites generated by micro-grooving or indents, these areas may be more susceptible to corrosion [17].

\subsection{Corrosion testing}

Two corrosion tests were performed on the three stainless steel types in an effort to obtain a specific wear rate due to mainly 'corrosion': (a) mechanical $-\mathrm{Al}_{2} \mathrm{O}_{3}$ ball rotated against each sample with only the corrosive electrolyte (no SiC abrasive) and (b) electrochemical-potentiodynamic polarisation of the steels in static electrolyte as described in Section 2.4.

\subsubsection{Alumina ball without SiC abrasive}

To help isolate the corrosion component enhanced by abrasion, an attempt was made to establish the corrosion only component under flowing electrolyte conditions induced by the rotating ball and any influence of crevices created by the ball and steel contact. A series of tests were performed within the ball-cratering rig with no $\mathrm{SiC}$ abrasive slurry but only using the $3.5 \% \mathrm{NaCl}$ solution. However, the contact between the ball and steel surface resulted in some passive film disruption and mild abrasion by the ball asperities. The scar diameter resulting from a combination of tribocorrosion, i.e. the continual depassivation/stripping of the passive film (simultaneous mechanical wear, electrochemical oxidation) was assessed and the specific wear rate determined. Table 5 lists for the values of $k$ obtained from these tests which will be referred to as RC (corrosion with rotation of the ball).

Table 5

The specific wear rate, $k$, for the three samples from the pure corrosion tests with only the alumina ball and no $\mathrm{SiC}$ abrasives

\begin{tabular}{ll}
\hline Samples & $k\left(\mathrm{~m}^{3} / \mathrm{Nm}\right)$ \\
\hline UNS S30403 & $1.25 \times 10^{-14}$ \\
UNS S31603 & $8.01 \times 10^{-14}$ \\
UNS S32760 & $2.88 \times 10^{-14}$ \\
\hline
\end{tabular}




\subsubsection{Potentiodynamic polarisation in $3.5 \mathrm{wt} . \% \mathrm{NaCl}$ solution}

Fig. 6 clearly shows that the more highly alloyed sample, S32760, has a superior corrosion performance compared with S30403 and S31603, remaining passive over a wide potential range with no evidence of pitting activity. Pitting is a well-known phenomenon for stainless steels which is reported to take place preferentially at inclusions within the microstructure situated at the exposed metal/solution interface, most notably manganese sulphide $(\mathrm{MnS})$ inclusions [18-22]. Overall, the pitting behaviour has been reported to depend on the most damaging sulphide inclusion; i.e. the largest inclusion [23]. Metastable pitting activity can be clearly seen for the $\mathrm{S} 30403$ as revealed by a series of transients from $-0.200 \mathrm{~V}$ to the breakdown potential at $+0.030 \mathrm{~V}$. Metastable pitting on stainless steels can be observed
Table 6

Summary of the values of $E_{\text {corr }}$ and $i_{\text {corr }}$ for the three samples

\begin{tabular}{lll}
\hline Samples & $i_{\text {corr }}\left(\mu \mathrm{A} / \mathrm{cm}^{2}\right)$ & $E_{\text {corr }}(\mathrm{V})$ \\
\hline UNS S30403 & 0.08 & -0.2285 \\
UNS S31603 & 0.06 & -0.1734 \\
UNS S32760 & 0.01 & -0.1416 \\
\hline
\end{tabular}

at potentials below the pitting potential, or above the pitting potential before the start of stable pitting [23]. In addition, the corrosion performance of S30403 when compared with S31603 and S32760 stainless steels is usually often related to the role of alloying molybdenum; it has been reported that the molybdenum changes the anodic dissolution kinetics of the active pit surface $[24,25]$. Table 6 details the values of corrosion potential

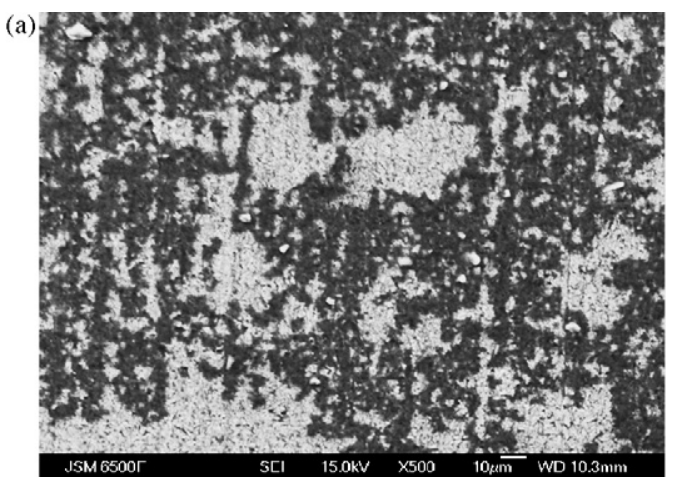

S30403 (two-body)

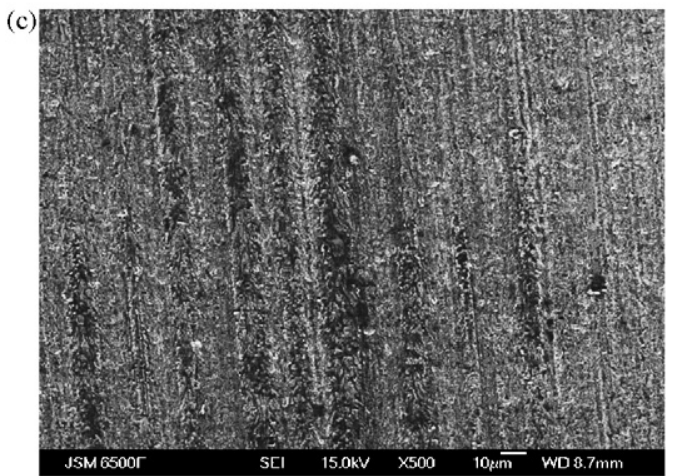

S32760 (two-body)

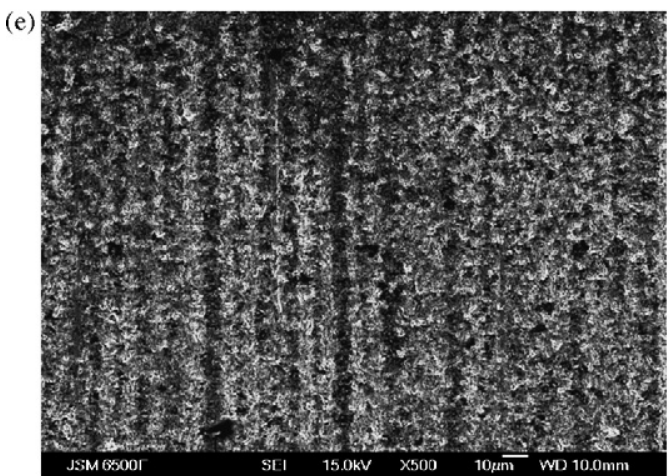

S31603 (mixed-mode)

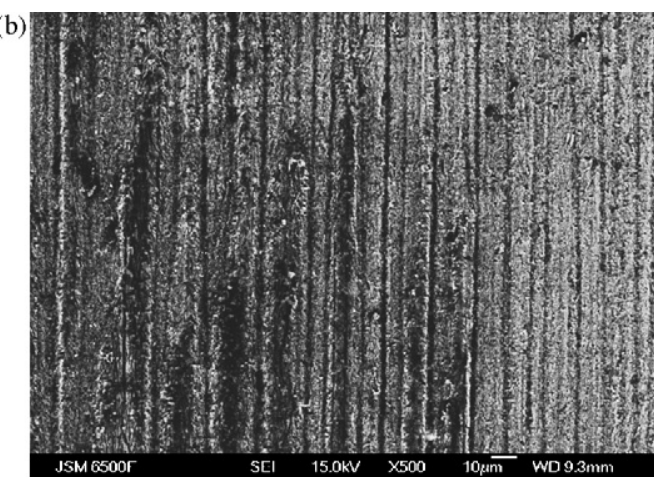

S31603 (two-body)

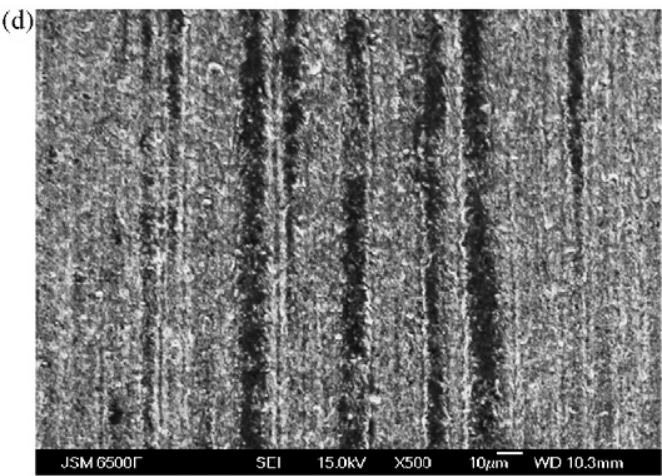

S30403 (mixed-mode)

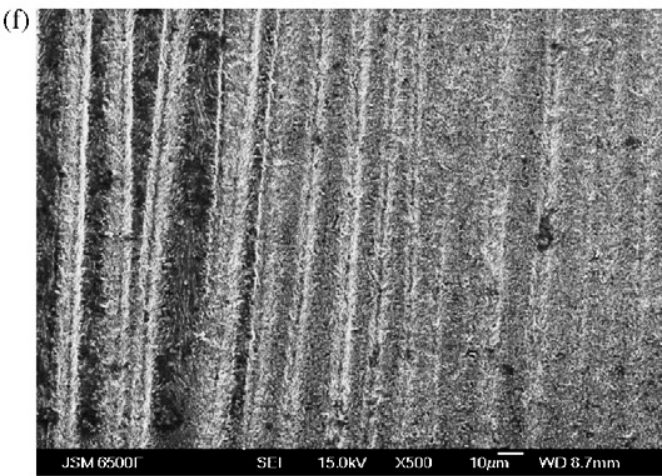

S32760 (mixcd-mode)

Fig. 5. SEM micrographs of UNS S30403, S31603 and S32760 stainless steels after being subjected to abrasion-corrosion (AC) and varying SiC abrasive volume faction. 


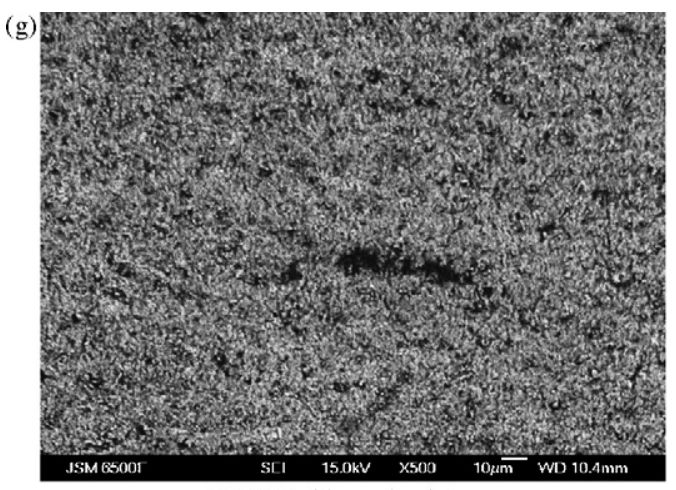

S30403 (three-body)

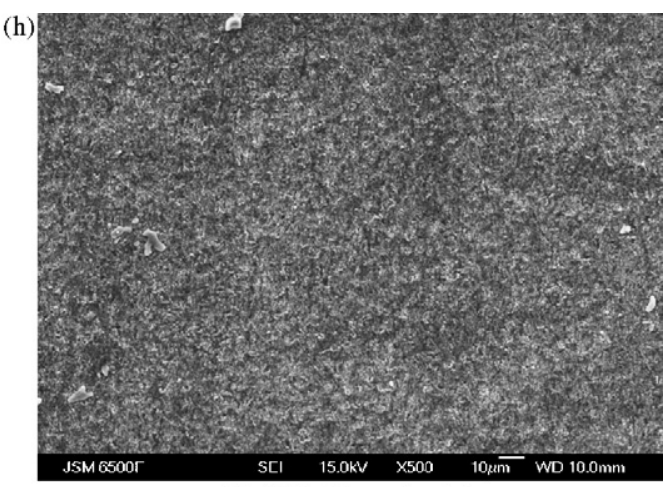

S31603 (three-body)

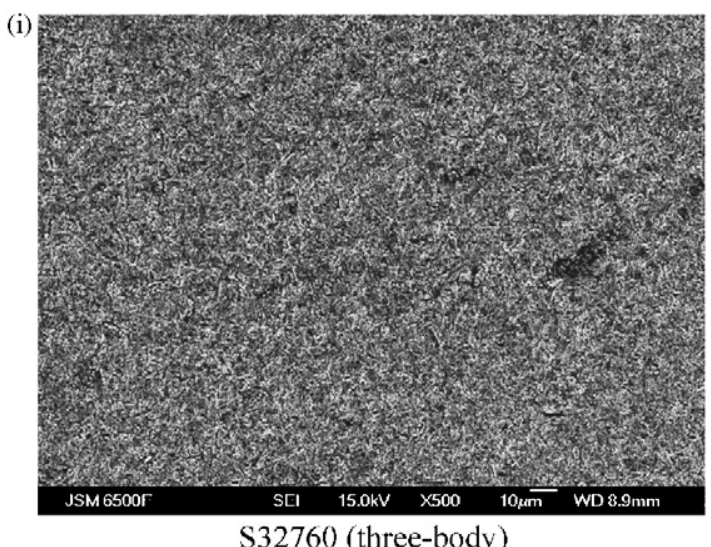

S32760 (three-body)

Fig. 5. (Continued).

$\left(E_{\text {corr }}\right)$ and the corresponding corrosion current density $\left(i_{\text {corr }}\right)$ for the three stainless steels. The $i_{\text {corr }}$ values were determined using the Tafel extrapolation method, from which the mass loss for a given time can be calculated using Faraday's law (see Eq. (5)) on the assumptions that the metallic components of the alloys are oxidised to $\mathrm{Fe}^{2+}, \mathrm{Cr}^{2+}, \mathrm{Ni}^{2+}$ and $\mathrm{Mo}^{6+}$ during dissolution:

$$
\frac{\Delta w}{t}=\frac{I M}{z F}
$$

where $\Delta w$ is the mass loss $(\mathrm{g}), t$ the test duration (s), $I$ the current ( $\mu \mathrm{A}), M$ the molar mass for the alloy, $z$ the number of electrons (calculated by composition) and $F$ is the Faraday con-

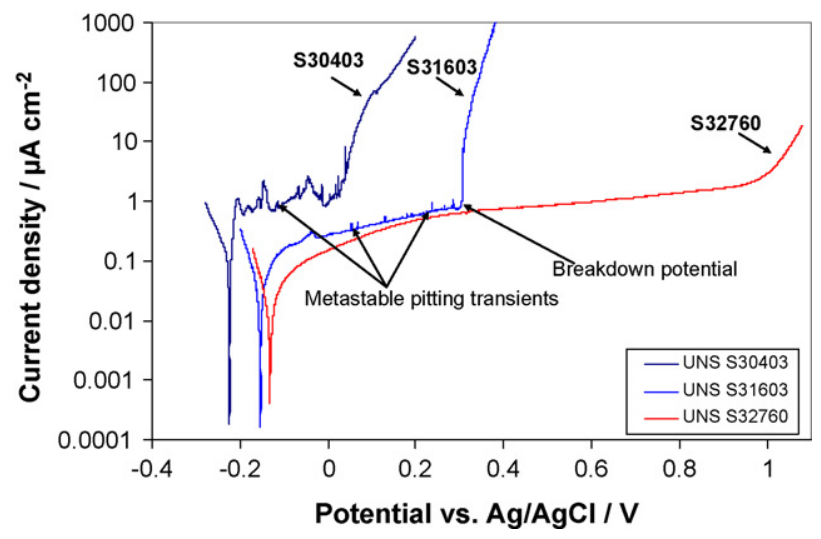

Fig. 6. Polarisation curves from pure (electrochemical) corrosion tests for the UNS S30403, S31603 and S32760 (sweep rate: $0.2 \mathrm{mV} / \mathrm{s}$ ). stant (96485 $\mathrm{A} \mathrm{s} \mathrm{mol}^{-1}$ ). The mass loss was converted to volume loss using a density of $7910 \mathrm{~kg} \mathrm{~m}^{-3}$.

Therefore, to calculate the mass loss and the equivalent specific wear rate, $k$, for the three stainless steels from the pure corrosion (polarisation) tests, the method described in a previous paper [26] was adopted using the data in Tables 1 and 2. The $k$ obtained, denoted as $C$, from the polarisation test is small compared with typical $k$ values obtained using the $\mathrm{Al}_{2} \mathrm{O}_{3}$ ball rotation and corrosive electrolyte. Ultimately, this will have an affect on the synergy analysis as discussed in Section 3.4.

\subsection{Synergistic effect}

Evaluating synergy during wear-corrosion processes has been a subject of much debate [27-29] and has at times reflected the use of measurements that are easily made. Some authors have suggested that corrosion leads to increase abrasion resistance in some materials [29], while others hold the opposite opinion. The results of abrasion-corrosion tests seem to be dependent more on techniques and test conditions adopted during any test. However, the ASTM G119-93 [31] has given a general guideline for determining synergy during wear-corrosion test. The current investigation has attempted to evaluate synergy via three approaches, allowing comparisons to be made between different methods of estimating synergy. Mathematically, these terms are listed below:

$S=\mathrm{AC}-\mathrm{PA}$ 
$S_{\mathrm{I}}=\mathrm{AC}-(\mathrm{PA}+\mathrm{RC})$

$S_{\text {II }}=\mathrm{AC}-(\mathrm{PA}+C)$

where $\mathrm{RC}$ is $k$ determined by rotating the alumina ball against the sample in the presence of corrosive electrolyte without SiC abrasive particles and will take galvanic affects between contact area and non-contact area into account. $C$ is $k$ determined from electrochemical tests (Section 3.3). Gant et al. [32] have attempted to evaluate synergy of some hard metals using Eq. (6) and but have not considered Eq. (8), which is equivalent to the ASTM [31] guidelines for estimating synergy. Eq. (7) is an attempt to develop Eq. (6) by including a dynamic corrosion term rather than a static corrosion rate which does not account for mass transport, micro-galvanic or crevice effects generated by ball/steel contact. The simplest approach, Eq. (6), is the most attractive; however, it does not accommodate the influence of corrosion. The research literature debates this as well and certain research groups have introduced $C$ from polarisation curves made under static conditions. However, by their nature polarisation type approaches will consider the whole wetted surface as opposed to the small active wear scar area that is formed during the micro-abrasion test. The alternative approach is to attempt to generate $\mathrm{RC}$ by rotating the counterface alumina ball against the sample in the presence of a corrosive electrolyte but with no $\mathrm{SiC}$ abrasive particles. This is likely to produce tribochemical wear but the alumina asperity will also induce additional mild mechanical abrasion. To understand the contributions of abrasion on corrosion $\left(\Delta A_{\mathrm{C}}\right)$ and of corrosion on abrasion $\left(\Delta C_{\mathrm{A}}\right)$ make to the synergistic levels, the ASTM recommends in situ electrochemical measurements. These have been shown to be difficult to interpret in the present work and will be the subject of future work. However, we can expand Eq. (8) to be rewritten as

$\mathrm{AC}=\mathrm{PA}+C+\Delta A_{\mathrm{C}}+\Delta C_{\mathrm{A}}$

Fig. 7 compares the calculated synergies, $S$ for all three samples at $180 \mathrm{~m}$. $S_{\text {II }}$ was not plotted since $C$ was typically $4.98 \times 10^{-17}$ and $5.25 \times 10^{-17} \mathrm{~m}^{3} / \mathrm{Nm}$ and as such has little overall effect on the synergy. As can be seen from the figure the relationship between $S$ and the volume fraction of abrasive is non-linear for all steels tested. As outlined above $C$ does not involve any mechanical input with the implication

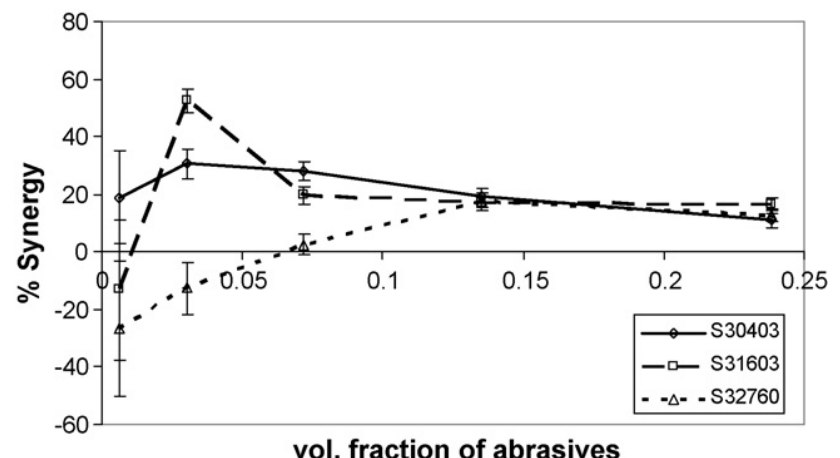

Fig. 7. Synergy\% (S) vs. volume fraction of the abrasives for UNS S30403, S31603 and S32760.

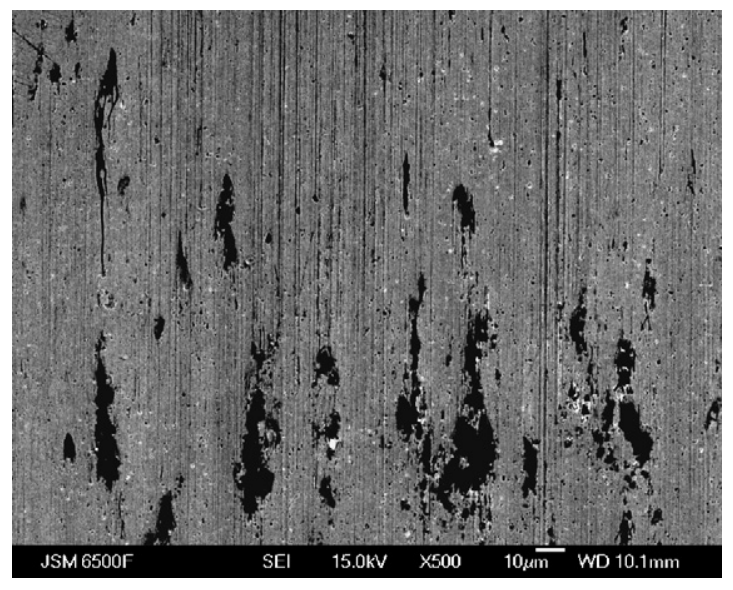

Fig. 8. SEM of UNS S31603 after corrosion testing RC using a rotating alumina ball without abrasives showing the effect of ball asperities.

that the passive film is not damaged or removed to any great extent. However, in the case of RC, the tribochemical wear and possibly alumina ball asperities continually remove the passive film exposing an active surface area of the material to the corrosive electrolyte. In addition, the formation of imperfect oxide films at plastic deformation sites during repassivation may have caused these areas to be more susceptible to corrosion, see Fig. 8 for the SEM of a S31606 sample tested under this condition.

It can be seen from Fig. 7 that the synergy resulting from a two-body wear mode was highly variable as evident by the large degree of scatter. Both S31603 and S32760 stainless steels produced negative values of $S$ under this wear condition while $S$ was positive for S30403. The large negative synergies produced by the two-body wear mechanism may be a reflection of the differences in repassivation kinetics and/or composition of the passive films reducing the overall level of two-body abrasion [26]. However, the mixed-mode region shows a significant reduction in scatter for each stainless steel. Likewise all three stainless steel types within the three-body region showed improved reproducibility with increasing volume fraction of abrasive. Rabinowicz et al. [33] in their study of abrasive wear under a three-body regime reported that three-body abrasion leads to more reproducible test results compared with twobody. Batchelor and Stachowiak [30] have also suggested that three-body abrasion is more effective in removing the corrosion products, and by implication any passive film present, during abrasion-corrosion. Fig. 7 also shows that under three-body wear, $S$ generally converges with increasing slurry concentration to a uniform positive synergy of $18 \%$ for the three stainless steels. The comparison between $S$ and $S_{\text {I }}$ for each stainless steel sample is shown in Figs. 9-11 and reveals a significant difference in synergy terms for two-body and mixed-mode regimes, compared with synergies within the three-body region. This result further demonstrates the inefficiency of two-body abrasion in removing the corrosion product and the lack of reproducibility of this wear mode. As expected, $S_{\text {I }}$ was observed to be lower than $S$ for all three stainless steel samples, since $S_{\text {I }}$ accommodates the presence of an associated corrosion component, RC 


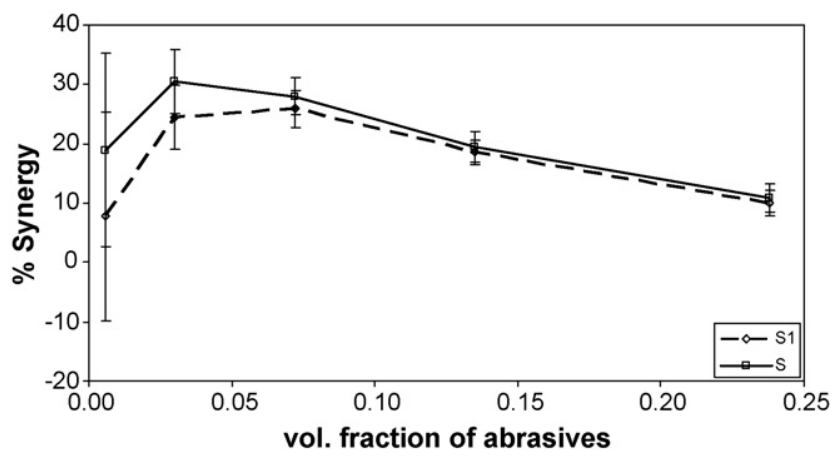

Fig. 9. Comparing $S$ and $S_{\text {I }}$ for UNS S30403.

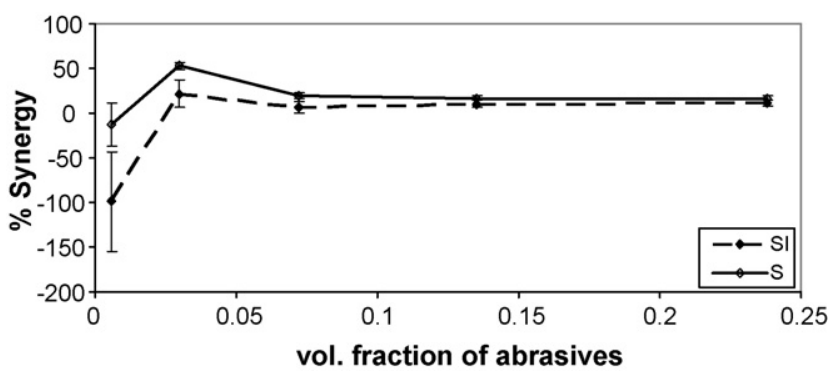

Fig. 10. Comparison of the $S$ and $S_{\text {I }}$ for UNS S31603.

(Eq. (6)) and results larger negative synergies at low volume fractions. Although it was hoped that RC would compensate for influences of the dynamic entrainment of the electrolyte, microgalvanic phenomena between worn and unworn surfaces and crevice influences, these effects were overwhelmed by tribochemical and mild abrasive processes induced by direct contact between the rotating ball and steel surfaces. Thus, emphasis will be placed on $S$ while the true position is likely to be that the actual synergy levels are between $S$ and $S_{\mathrm{I}}$.

To establish the balance between mechanical and electrochemical degradation the data have been graphically represented on a mechanistic map where AC-PA (electrochemical processes/losses) is plotted against PA (mechanical processes/losses), see Fig. 12. The term AC-PA represents the electrochemical contribution to synergy if $\Delta A_{\mathrm{C}}$ is assumed to be negligible. It is apparent that the majority of the data for the

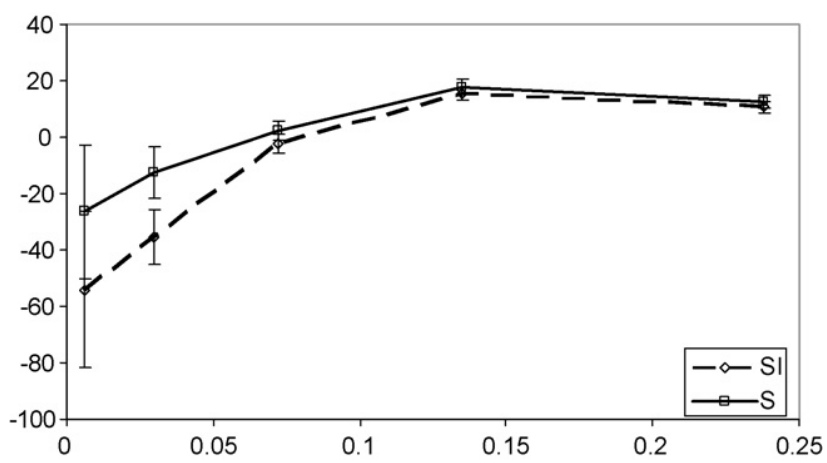

Fig. 11. Comparison of the $S$ and $S_{\text {I }}$ for UNS S32760.

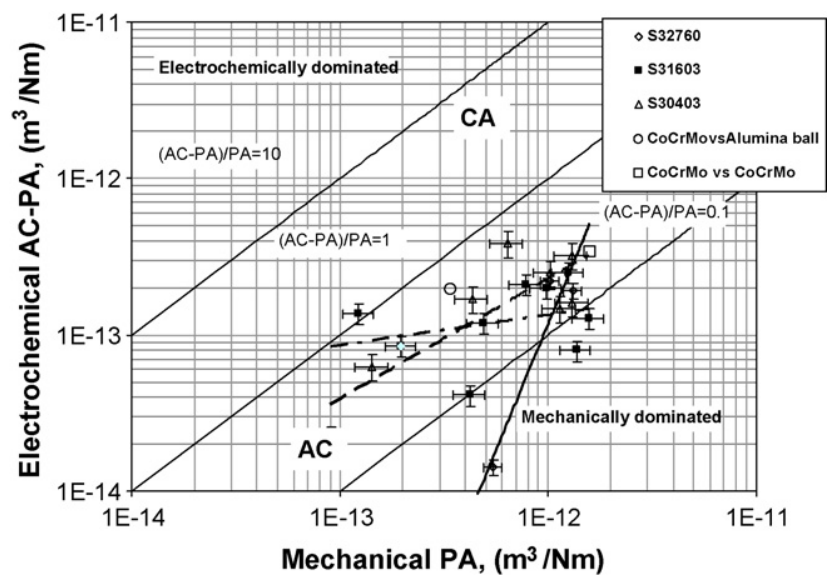

Fig. 12. Mapping of AC-PA for all the UNS S30403, S31603 and S32760 against PA. Where AC and CA are the abrasion-corrosion and corrosion-abrasive regimes, respectively. Note: The negative synergy points for S32760 are not plotted. Also plotted for comparison are points for CoCrMo obtained using similar test techniques but with Ringers solution [34].

Table 7

Relationships between synergy levels $S$ and mechanical wear levels PA

\begin{tabular}{llll}
\hline Material & Equation & Constant $A$ & Equation number \\
\hline S30403 & $S=A(\mathrm{PA})^{0.77}$ & $4 \mathrm{E}-4$ & $(6)$ \\
S31603 & $S=A(\mathrm{PA})^{0.19}$ & $3 \mathrm{E}-11$ & $(7)$ \\
S32760 & $S=A(\mathrm{PA})^{3.32}$ & $6 \mathrm{E}+25$ & $(8)$ \\
\hline
\end{tabular}

three stainless steels are in the abrasion-corrosion regime where the material losses by mechanical processes are equal to or up to ten times the losses due to electrochemical processes. It is interesting to note (albeit tentatively) the variation in trends for the three steels on this map, although the errors are high. The equations for the power law trends are given in Table 7.

If the electrochemical and mechanical contributions to total material loss are balanced then $S=A(\mathrm{PA})^{1.00}$. From Table 7 is clear that S30403 is closest to this case indicating that repassivation effects are negligible and that as the wear sites or intensity increases the electrochemical response increases as the depassivation rate outstrips the repassivation rate. This is in contrast to $\mathrm{S} 31603$ where $S$ is almost independent of the level of PA, indicating stronger repassivation than S30403 such that repassivation equals depassivation rates. The $S$ results for $\mathrm{S} 32760$ are mainly negative and therefore are not plotted in Fig. 12 but the conditions that give positive $S$ show a high sensitivity to PA. This suggests that the passive film remains intact (giving negative or very low positive synergies) until PA reaches $1 \times 10^{-12} \mathrm{~m}^{3} / \mathrm{Nm}$ then the film is suddenly ruptured or removed with the consequence that $S$ levels are comparable to those of S30403 and S31603 at these high PA values where mechanical abrasion losses are 10 times those of electrochemical losses and little material type has little influence over $S$ levels.

\section{Conclusions}

- The specific wear rate, $k$, generally increases with increasing abrasive volume fraction for both pure abrasion and 
abrasion-corrosion tests, for all the three stainless steels. The three-body wear mode generally has abrasion-corrosion rates that are about 14 times higher than two-body.

- The abrasive particle volume fraction influenced the degree of synergy in a non-linear manner. For S31603 and S32760 a negative synergy was seen for two-body abrasion while a positive synergy was seen for mixed and three-body abrasion. For S30403, only positive synergies were seen and this behaviour was attributed to $\mathrm{S} 30403$ having weaker repassivation/passive oxide film structure.

- In this study, two-body abrasion showed greater inconsistency than three-body for abrasion-corrosion, evident by the relatively high scatter in the synergy.

- The overall relative performance of the three stainless steels showed that S32760 was superior to S31603 and S30403, which can be attributed to its excellent corrosion resistance and repassivation kinetics.

- A mechanistic abrasion-corrosion map has been developed to establish the overall influence between electrochemical and mechanical degradation processes. This plots $S$ (electrochemical contribution from corrosion synergy) against PA (mechanical contribution from abrasion). Variations in trends for the three steels are seen. For S30403, the electrochemical and mechanical contributions to total material loss are balanced indicating that repassivation effects are negligible and that as the wear intensity increases the electrochemical response increases due to the depassivation rate outstripping the repassivation rate. This is in contrast to $\mathrm{S} 31603$ where $S$ is almost independent of the level of PA, indicating stronger repassivation such that repassivation equals depassivation rates. For S32760, the passive film remains intact (giving negative or very low positive synergies) until PA reaches $1 \times 10^{-12} \mathrm{~m}^{3} / \mathrm{Nm}$ then the film is suddenly ruptured or removed with the consequence that $S$ levels are comparable to those of S30403 and S31603.

- Although an attempt was made to include the corrosion rate induced by the rotating ball, the tribo-chemical and mild abrasion this contact causes made this interpretation difficult. Therefore, for stainless steels, $S$ should be calculated simply by $S=$ AC-PA.

\section{Acknowledgement}

The authors would like to acknowledge the support of the School of Engineering Sciences, University of Southampton in undertaking this work.

\section{References}

[1] O. Acselrad, A. Ribeiro de Souza, I.S. Kalashnikov, S.S. Camargo, A first evaluation of the abrasive wear of an austenitic FeMnAlC steel, Wear 257 (2004) 999-1005.

[2] G. Abbas, U. Ghazanfar, Two-body abrasive wear studies of laser produced stainless steel and stainless steel plus SiC composite clads, Wear 258 (2005) 258-264.

[3] A. Van Herpen, B. Reynier, C. Phalippou, Effect of test duration on impact/sliding wear damage of $304 \mathrm{~L}$ stainless steel at room tempera- ture: metallurgical and micromechanical investigations, Wear 249 (2001) $37-49$.

[4] M. Reza Bateni, J.A. Szpunar, X. Wang, D.Y. Li, Wear and corrosion wear of medium carbon steel and 304 stainless steel, Wear 260 (1-2) (2006) 116-122.

[5] I. Garcia, D. Drees, J.P. Celis, Corrosion-wear of passivating materials in sliding contacts based on a concept of active wear track area, Wear 249 (2001) 452-460.

[6] U.I. Thomann, P.J. Uggowitzer, Wear-corrosion behavior of biocompatible austenitic stainless steels, Wear 239 (2000) 48-58.

[7] P.A. Dearnley, G. Aldrich-Smith, Corrosion-wear mechanisms of hard coated austenitic 316L stainless steels, Wear 256 (2004) 491-499.

[8] C. Allen, A. Ball, B.E. Protheroe, The abrasive-corrosive wear of stainless steels, Wear 74 (1981) 287-305.

[9] M.H. Hong, S.I. Pyun, Corrosive wear behavior of 304L stainless-steel in $1 \mathrm{~N} \mathrm{H}_{2} \mathrm{SO}_{4}$ solution. 2. Effect of chloride-ion concentration, Wear 147 (1991) 69-78.

[10] C.W. Wu, Corrosion wear study of 304 stainless-steel in various $\mathrm{NaCl}$ solutions, Wear 162 (1993) 950-953.

[11] C.K. Lee, H.C. Shih, The abrasive corrosive wear of plasma-nitrided alloy steels in chloride environment, J. Mater. Sci. 35 (9) (2000) 23612369.

[12] J.R. Goldberg, J.L. Gilbert, Electrochemical response of CoCrMo to highspeed fracture of its metal oxide using an electrochemical scratch test method, J. Biomed. Mater. Res. 37 (1997) 421-431.

[13] S. Mischler, S. Debaud, D. Landolt, Wear-accelerated corrosion of passive metals in tribocorrosion systems, J. Electrochem. Soc. 145 (3) (1998) $750-758$.

[14] M. Stemp, S. Mischler, D. Landolt, The effect of mechanical and electromechanical parameters on the tribocorrosion rate of stainless steel in sulphuric acid, Wear 255 (2003) 466-475.

[15] S. Mischler, A. Spiegel, D. Landolt, The role of passive oxide films on the degradation of steel in tribocorrosion systems, Wear 225-229 (1999) 1078-1087.

[16] K. Adachi, I.M. Hutchings, Wear-mode mapping for the micro-scale abrasion test, Wear 255 (2003) 23-29.

[17] L.L. Shreir, R.A. Jarman, G.T. Burstein (Eds.), Corrosion, 3rd ed., Butterworth-Heinemann, Oxford, UK, 1994.

[18] G. Wranglen, Pitting and sulfide inclusions in steel, Corros. Sci. 14 (1974) 331-349.

[19] J.E. Castle, R. Ke, Studies by auger-spectroscopy of pit initiation at the site of inclusions in stainless-steel, Corros. Sci. 30 (1990) 409-428.

[20] D.E. Williams, J. Stewart, P.H. Balkwill, The nucleation, growth and stability of micropits in stainless-steel, Corros. Sci. 36 (1994) 1213-1235.

[21] P.C. Pistorius, G.T. Burstein, Metastable pitting corrosion of stainlesssteel and the transition to stability, Phil. Trans. Roy. Soc. A 341 (1992) 531-559.

[22] J.A. Wharton, R.J.K. Wood, B.G. Mellor, Wavelet analysis of electrochemical noise measurements during corrosion of austenitic and super duplex stainless steels in chloride media, Corros. Sci. 45 (2003) 97-122.

[23] J. Stewart, D.E. Williams, The initiation of pitting corrosion on austenitic stainless-steel—on the role and importance of sulfide inclusions, Corros. Sci. 33 (1992) 457-463.

[24] R.R. Ke, R. Alkire, Initiation of corrosion pits at inclusions on 304 stainless steel, J. Electrochem. Soc. 142 (1995) 4056-4062.

[25] G.O. Ilevbare, G.T. Burstein, The role of alloyed molybdenum in the inhibition of pitting corrosion in stainless steels, Corros. Sci. 43 (2001) 485-513.

[26] J.O. Bello, R.J.K. Wood, J.A. Wharton, Micro-abrasion-corrosion of UNSS31603L stainless steel, in: Proceedings of the IRG-OEDC on Wear of Engineering Materials, Uppsala, Sweden, June 2005.

[27] W. Schumacher, Service validation of corrosive wear synergy, Wear 250 (2001) 1279-1283.

[28] F. Assi, H. Bohni, Study of wear-corrosion synergy with a new microelectrochemical technique, Wear 235 (1999) 505-514.

[29] F. Ferrer, H. Idrissi, H. Mazille, P. Fleischmann, P. Labeeuw, A study of abrasion-corrosion of AISI 304L austenitic stainless steel in saline solution using acoustic emission technique, NDT \& E Int. 33 (6) (2000) 363-371. 
[30] A.W. Batchelor, G.W. Stachowiak, Predicting synergism between corrosion and abrasive wear, Wear 123 (1998) 281-291.

[31] ASTM G119-93, Standard Guide for Determining Synergism Between Wear and Corrosion, ASTM Handbook, 1998, pp. 529-534.

[32] A.J. Gant, M.G. Gee, A.T. May, The evaluation of tribo-corrosion synergy for WC-Co hardmetals in low stress abrasion, Wear 256 (2004) 500-516.
[33] E. Rabinowicz, L.A. Dunn, P.G. Russell, A study of abrasive wear under three-body conditions, Wear 4 (1961) 345-355.

[34] P.E. Sinnett-Jones, J.A. Wharton, R.J.K. Wood, Micro-abrasion-corrosion of a CoCrMo alloy in simulated artificial hip joint environments, Wear 259 (2005) 898-909. 